\section{BiCentenario de DARWIN}

\section{DARWIN'S BICENTENNIAL}

Sr. Editor: Con ocasión de celebrarse este año el bicentenario del nacimiento de Charles Darwin (1809-1882) y recordar su Teoría de la Evolución, estimo conveniente citar las publicaciones referentes a su obra aparecidas en esta Revista desde el siglo XIX. En efecto, en octubre de 1993 se efectuó en Santiago un Simposio Internacional sobre el viaje de Darwin a Chile, en 1835. Se presentó un trabajo que describió la historia de la participación de personalidades en la introducción de la Teoría de la Evolución en Chile, desde la fundación de esta Revista hasta la época actual ${ }^{1}$. La enseñanza de esta teoría en la Cátedra de Biología de la Universidad de Chile la desarrolló el Profesor Juan Noé entre 1923 y 1947, en la que describió la teoría de la herencia mendeliana, que complementó con los principios del neodarwinis$\mathrm{mo}^{2}$.

La idea matriz de Darwin en su libro sobre el Origen de la Especies (1859), es la "Selección Natural", que dentro del componente genético de la teoría de la evolución se transforma en la primera fuerza sistemática del proceso de cambios de los organismos vivos. Los genetistas chilenos investigaron los grados de selección natural en las poblaciones humanas ${ }^{3}$ y en los problemas sanitarios nacionales de mortalidad, morbilidad y reproducción $n^{4,5}$ demostrando en forma concluyente estos efectos.

Durante la segunda mitad del siglo XX, los genetistas nacionales efectuaron investigaciones de campo en poblaciones aborígenes chilenas logrando evaluar las fuerzas naturales de la evolución biológica relacionadas con la demografía y la salud pública ${ }^{6,7}$. Las conclusiones de estos traba- jos permiten sostener una Teoría de Genética de Poblaciones, la que estima que la población humana va cambiando gradualmente por el efecto de las fuerzas sistemáticas evolutivas: mutación, selección natural y migración, a las que se oponen las fuerzas dispersivas de la endogamia y la deriva probabilística. A estas referencias, citadas en esta Revista, sus autores han publicado las siguientes monografías que abordan en forma completa esta Teoría: Curso Básico de Genética Humana, 1977 (Rothhammer \& Cruz-Coke), Color Blindness, an evolutionary approach, 1970 (Cruz-Coke); The Aymarae, 1990 (Schull \& Rothhammer); Poblaciones Chilenas, 2004 (Rothhammer \& Llop).

\section{Dr. Ricardo Cruz-Coke M.}

Profesor de Medicina, Universidad de Chile

\section{REFERENCIAS}

1. Cruz-Coke R. La Teoría de la Evolución en las ciencias médicas en Chile. Rev Méd Chile 1994; 122: 211-14.

2. Cruz-Coke R. La genética clásica del Profesor Noé. Rev Méd Chile 1993; 121: 581-7.

3. Rothhammer F, Covarrubias R, Cruz-Coke R, Valenzuela CY. Selección natural en poblaciones humanas. Rev Méd Chile 1975; 103: 44-8.

4. Cruz-Coke R, Urquiza A, Weiser G, Vera R. Mortalidad infantil y seleccion natural. Rev Méd Chile 1971; 99: 473-9.

5. CRUZ-COKE R. Evidencias demográficas de relajación de la selección natural en el hombre. Rev Méd Chile 1979; 107: 652-4.

6. Cruz-Coke R, Cristoffanini AP, Biancani F, Aspillaga M. Fuerzas evolutivas en poblaciones andinas. Rev Méd Chile 1966; 94; 586-91.

7. Cruz-Coke R. Los genes del pueblo pascuense. Rev Méd Chile 1989; 117: 804-12. 